\title{
Pneumologia
}

\section{Cystic echinococcosis: An attraction for fungal and bacterial pulmonary infections}

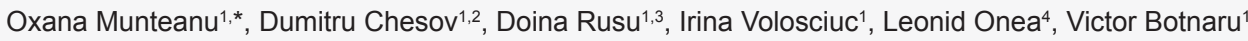 \\ ${ }^{1}$ Department of Internal Medicine, Division of Pneumology and Allergology, State University of Medicine and Pharmacy 'Nicolae Testemitanu', \\ Chisinau, Republic of Moldova \\ ${ }^{2}$ Department of Clinical Infectious Diseases, Research Center Borstel, Borstel, Germany \\ ${ }^{3}$ Department of Pneumology, Phthisiopneumology Institute 'Chiril Draganiuc', Chisinau, Republic of Moldova \\ Abstract \\ ${ }^{4}$ Department of Radiology, German Diagnostic Center, Chisinau, Republic of Moldova

\section{English:} \\ Lung hydatidosis can remain latent for a long time, and symptoms may occur when the cysts grow to a certain size or when \\ symptoms arise secondary to complications such as rupture or superinfection with bacterial organisms or fungi. A variety of \\ signs denoting different appearances of complicated and/or uncomplicated pulmonary hydatid cysts have been described on \\ chest radiographs and computed tomography scans. Aspergillosis is one of the most common fungal infections associated with \\ pre-existing pulmonary cavities. The coexistence of aspergillosis and hydatid cyst is rare. Citrobacter infections usually occur in \\ patients with underlying co-morbidities or immunosuppression. We presented a case of pulmonary echinococcosis with multiple \\ bilateral cysts in which several consecutive episodes of cysts rupture and concomitant Aspergillus and Citrobacter pulmonary \\ infections have been documented.
}

Keywords

pulmonary echinococcosis $\bullet$ aspergillosis $\bullet$ imaging $\bullet$ Citrobacter $\bullet$ pneumonia $\bullet$ hydatid disease

\section{Echinococcoza pulmonară: Un magnet pentru infecțiile bacteriene și fungice pulmonare}

Rezumat

\section{Romanian:}

Hidatidoza pulmonară poate rămâne latentă mult timp, iar simptomele pot apărea când chistele cresc la o anumită dimensiune sau secundar unor complicații, ca ruptura sau suprainfecția chistelor cu organisme bacteriene sau fungice. Au fost descrise o multitudine de semne radiografice și CT ce relevă diferite aspecte ale chistelor hidatice pulmonare complicate sau necomplicate. Aspergiloza este una din cele mai obișnite infectii fungice asociate cu cavitătile pulmonare preexistente. Coexistenta aspergilozei cu chistele hidatice este rară. Infecția cu Citrobacter apare de obicei la pacienți cu comorbidități subiacente și imunodepresie. Prezentăm un caz de echinococcoză pulmonară cu chiste multiple bilaterale la care au fost evidențiate mai multe episoade consecutive de ruptură a chistelor și infecție concomitentă cu Aspergillus și Citrobacter.

Cuvinte-cheie

echinococcoză pulmonară • aspergiloză • imagistică • Citrobacter • pneumonie • boală hidatică

${ }^{*}$ Corresponding author: Oxana Munteanu, Associate Professor, Department of Internal Medicine, Division of Pneumology and Allergology, State University of Medicine and Pharmacy 'Nicolae Testemitanu', Chisinau, Republic of Moldova.

E-mail: oxana.munteanu@usmf.md

ว Open Access. ๑ 2020 Munteanu et al., published by Sciendo

(c) Br-Nc-ND This work is licensed under the Creative Commons Attribution-NonCommercial-NoDerivs 4.0 License. 


\section{Introduction}

Cystic echinococcosis or hydatid disease affects 1 million people every year worldwide (1). Cystic lesions associated with hydatid disease are caused by the larvae of the tapeworm Echinococcus and they commonly involve liver ( $70 \%)$ and lung $(\sim 20 \%)(2,3)$. Most patients have a single cyst in a single organ. However, one-third of the patients with pulmonary echinococcosis have multiple cystic lesions, and in $20 \%$ of cases they are bilateral $(2,4)$. Clinical features of the disease depend on the cysts size or induced complications. Small cysts may remain asymptomatic indefinitely. Symptomatic hydatid disease of the lung more often follows rupture of the cysts $(1,3,5)$. The rupture can occur either spontaneously or due to trauma or secondary infections. Several secondary infections, including viridans group streptococci, cryptococcosis and aspergillosis, have been reported to be associated with pulmonary hydatid cysts (HCs) (6-8). Here we present a case of a symptomatic pulmonary echinococcosis with multiple bilateral cysts in which several consecutive episodes of cysts rupture and concomitant Aspergillus and Citrobacter pulmonary infections have been documented.

\section{Case report}

A 68-year-old man presented to pulmonology outpatient department in March 2018 with a 2-month history of productive cough with sputum production (initially $100 \mathrm{~mL} /$ day of grey sputum and sometimes with solid white pieces, which had gradually become purulent). He was treated with amoxicillin orally for 10 days, but due to worsening conditions (severe left chest pain, fever $39^{\circ} \mathrm{C}$ and breathlessness) he was hospitalised. The patient has never smoked, but he reported biomass fuel exposure. His medical history was significant for liver cirrhosis, atrial fibrillation, arterial hypertension and New York Heart Association (NYHA) third-class heart failure. No chest radiographs were performed in the previous 10 years. Also, he had reported a prolonged exposure to dog and sheep. On chest radiography, the displacement of the trachea to the right, an apparent elevation of the left hemidiaphragm, bibasilar opacities and ill-defined cavities suggestive for the formation of lung abscess or cystic bronchiectasis were seen (Figure 1). Treatment with ceftriaxone and metronidazole was started. Mild eosinophilia ( 819 cells $/ \mu \mathrm{L}$ ), thrombocytopaenia (platelet count $120 \times 10^{3} / \mu \mathrm{L}$, attributed to hypersplenism) and moderate increase in erythrocyte sedimentation rate $(36 \mathrm{~mm} / \mathrm{h})$ were identified. Low total protein level and hypoalbuminaemia secondary to his cirrhosis were also found. On the 6-th day of admission, a thoracic high-resolution computer tomography (HRCT) was performed (Figure 2). This revealed three well-defined cavitary lesions with different contents. In

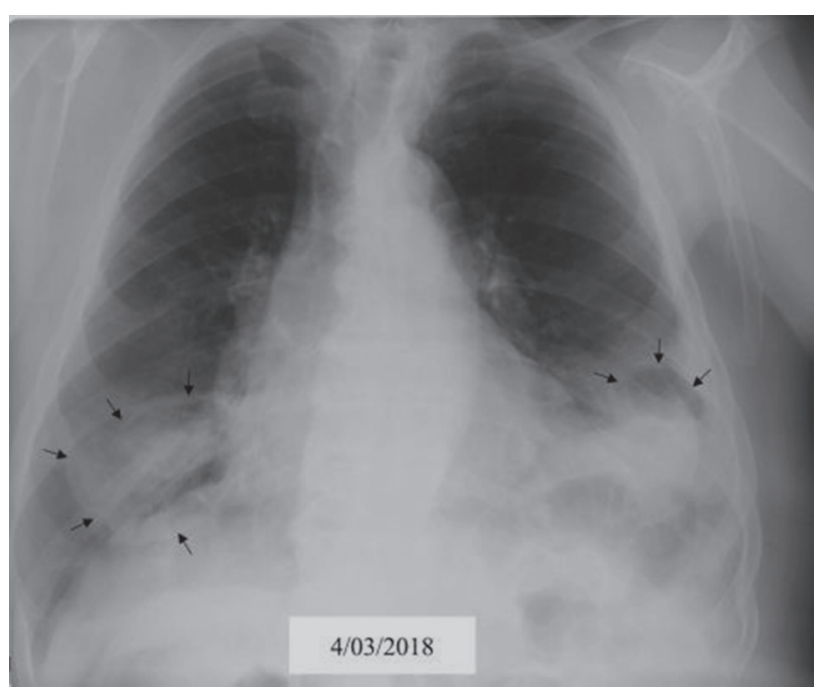

Figure 1. Posteroanterior view of chest X-ray showing bibasilar opacities and ill-defined cavities (arrows) suggestive for forming lung abscess or cystic bronchiectasis. Note the elevation of the left hemidiaphragm with mediastinal shift and displacement of the trachea to the right.

the left upper lobe, a well-circumscribed lesion (Figure $2 \mathrm{~A}$ and $\mathrm{B}$ ) around $4 \mathrm{~cm}$ in diameter, with smooth walls, predominantly of fluid attenuation content (12 HU) was identified. In the left lower lobe anteromedial segment, the lesion was $5 \mathrm{~cm}$ in diameter with thickened irregular walls (Figure 2D-F), dense content and the air crescent signs (moon sign and meniscus sign). In the right lower lobe posterolateral segment, another 5-cm thin-walled cavity with lobulated air-soft tissue interface ('air bubble' sign suggestive for ruptured and infected $\mathrm{HC}$ ) was found (Figure $2 \mathrm{G}$ and $\mathrm{H}$ ). No liver involvement was documented.

Serum Echinococcus granulosus IgG was positive $(3 \mathrm{U} / \mathrm{mL}$, normal range $<0.9 \mathrm{U} / \mathrm{mL}$ ) while Aspergillus fumigatus Ig $\mathrm{G}$ and galactomannan were both negative. Sputum cultures were negative for gram-positive bacteria, gram-negative bacteria and Mycobacterium tuberculosis but positive for Aspergillus niger (Figure 3).

A fiberoptic bronchoscopy was performed and it did not reveal any abnormality. Culture and microscopy of bronchoalveolar lavage (BAL) were also negative for gram-negative and grampositive bacteria as well as for M. tuberculosis. However, BAL galactomannan was positive.

The multiple round cysts and positive E. granulosus serology confirmed disseminated lung hydatidosis. At the same time, the air crescent sign (suggestive for pulmonary aspergilloma), positive sputum culture for $A$. nigerand positive galactomannan from BAL supported a concomitant pulmonary aspergillosis, probably by secondary fungi colonisation of pre-existing echinococcal cavity. 


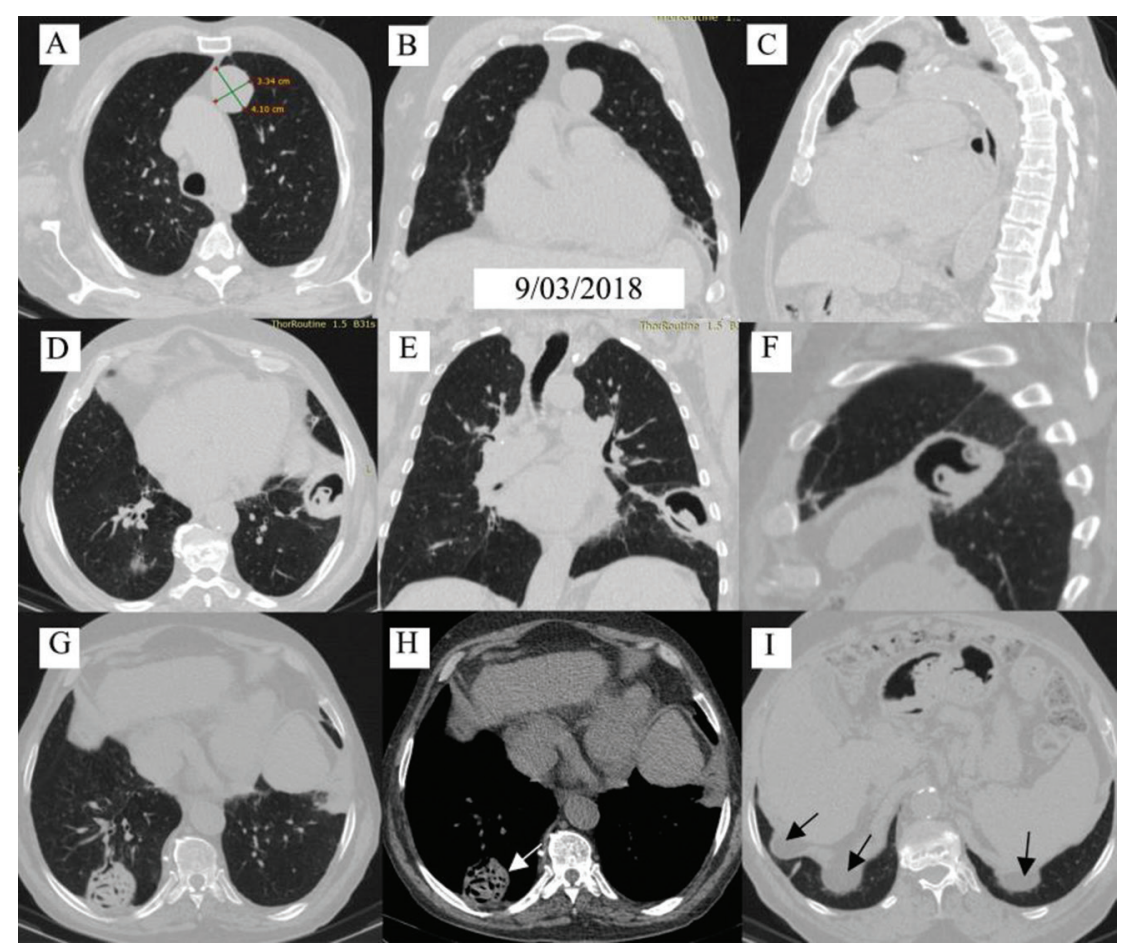

Figure 2. The high-resolution computer tomography images demonstrate three well-defined cavitary lesion with different inside contents. A (axial reconstruction), B (coronal reconstruction) and C (sagittal reconstruction) demonstrate a well-circumscribed lesion around $4 \mathrm{~cm}$ in diameter, with thin, smooth walls, predominantly of fluid attenuation inside $(12 \mathrm{HU})$ in the left upper lobe. D (axial reconstruction), $\mathbf{E}$ (coronal reconstruction) and $\mathbf{F}$ (sagittal reconstruction) show a cavitary lesion around $5 \mathrm{~cm}$ in diameter with thickened irregular walls, dense content inside and the air crescent sign (moon sign and meniscus sign) in the left lower lobe anteromedial segment. G (axial reconstruction, parenchymal window) and $\mathbf{H}$ (axial reconstruction, mediastinal window) show a 5-cm thin-walled cavity communicated with the airway with lobulated air-soft tissue interface (small air bubbles within the perforated pulmonary cysts - 'air bubble' sign, white arrow) in the right lower lobe posterolateral segment. (I) CT shows a defect in the right and left diaphragm with herniation of retroperitoneal fat tissue into the thorax (black arrows).

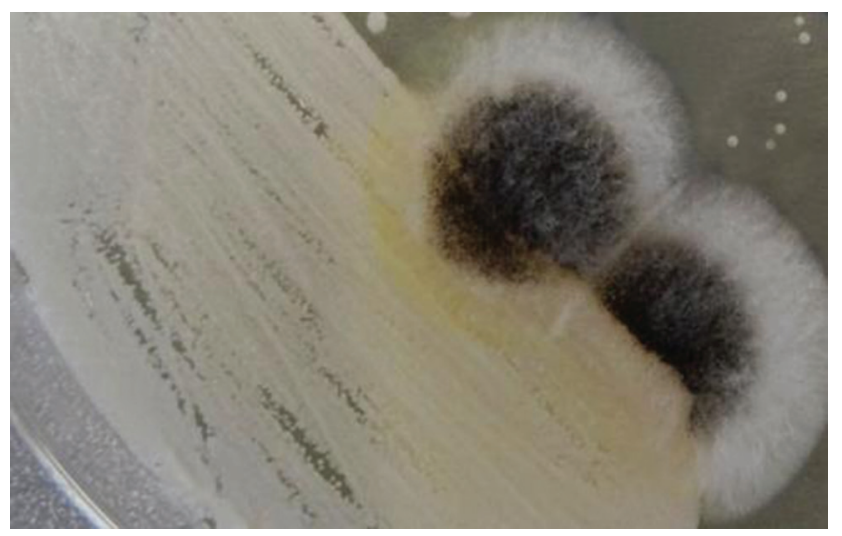

Figure 3. Colony of Aspergillus niger (black colonies) and Candida albicans (white colonies) on Sabouraud-Dextrose-Agar sputum culture.

Due to multiple lung cysts and associated co-morbidities, surgery was not considered and albendazole plus itraconazole in standard doses were started. The treatment was interrupted after 1 month due to side effects (nausea, vomiting and loss of appetite). The patient continued to complain of dry cough and moderate dyspnoea.

Three months later, a follow-up CT showed the upper left lobe cyst (Figure 4A and B) unchanged in size, borders and density (2-3 HU). A reduction in size of the right (Figure 4C and D) and left (Figure 4E and F) lower lobes cysts with an increased density of the content (30-60 HU) was observed.

In August 2018, after 6 months since the initial hospitalisation, the patient was admitted again for a new episode of severe dyspnoea, left side chest pain, cough and high fever. Chest radiography showed new areas of consolidation in the lower lung fields (Figure 5A). A communicating rupture of the upper left lobe cyst or bacterial superinfection was suspected. Antibiotic treatment with ceftriaxon and ciprofloxacin was initiated. Five days later, chest radiography showed partial resolution of pulmonary infiltrates on the left side (Figure 5B). Citrobacter freundii monoresistant to amoxicillin was isolated from the sputum. After 10 days of antibiotics, a follow-up radiography identified a decrease in the intensity of the left basal opacity and persistence of the previous cysts in the right 


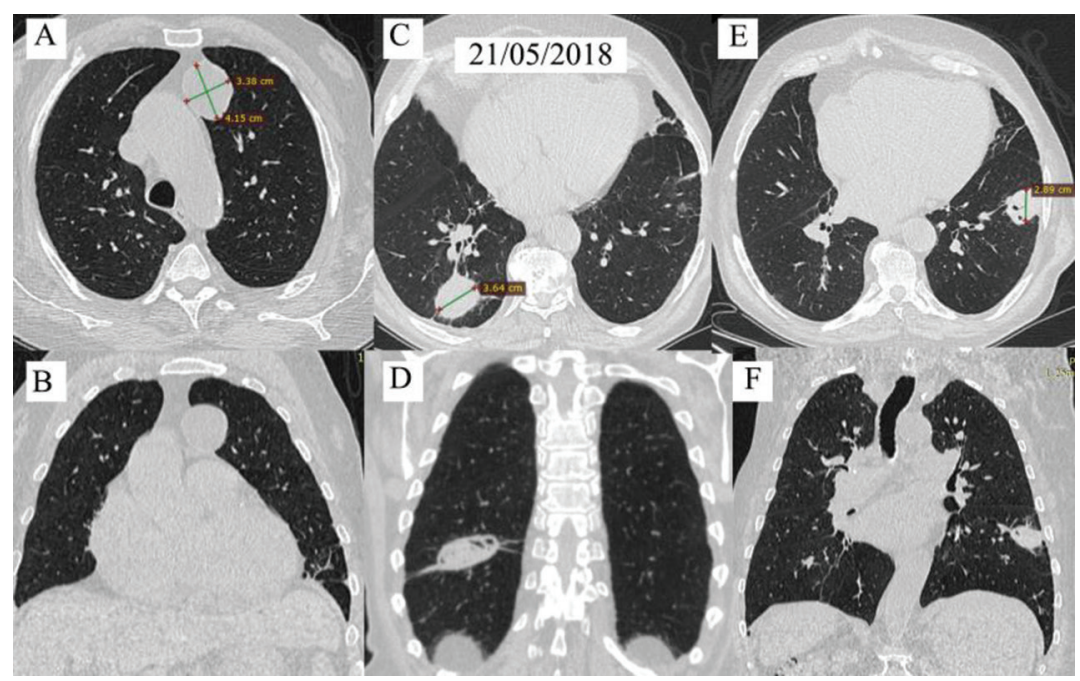

Figure 4. A follow-up CT (3 months later) shows the upper left lobe cyst (A, B) unchanged in size, borders and density (2-3 HU). A reduction in size of the right (C, D) and left (E, F) lower lobes cysts with an increased density of the inside content (30-60 HU) was observed. Note the presence of 'air bubble' sign in both lower lobe cysts (D, E).

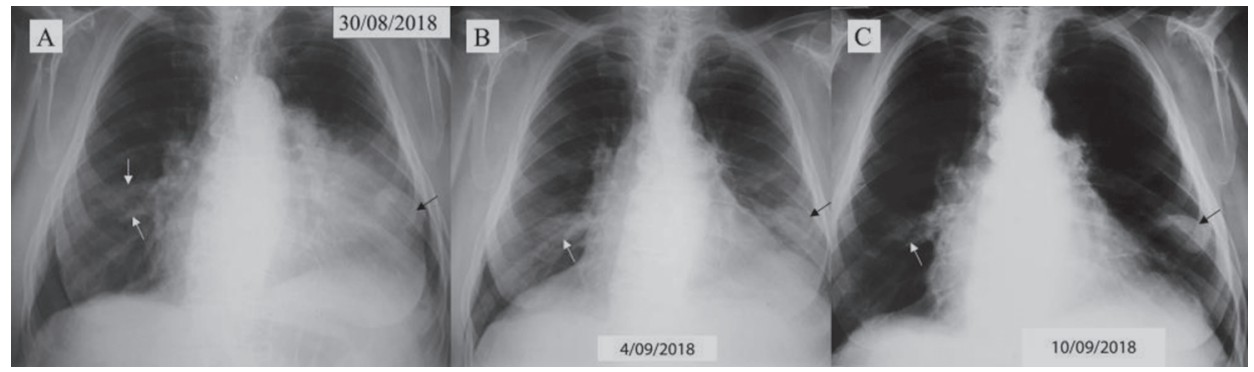

Figure 5. A: Posteroanterior chest radiography shows a pulmonary mass (round dense opacity) in the left lower field (black arrow), surrounded by ill-defined left paracardiac and perihilar opacity (note the air bronchogram and silhouette signs proving consolidation) and elevation of the left hemidiaphragm. A round ill-defined heterogeneous opacity (white arrows) on the right side was found. B: Five days later, chest radiography shows partial resolution of pulmonary infiltrates on the left side with persistence of the pulmonary masses in both lower lung fields (arrows). C: A follow-up radiography after 10 days of antibacterial treatment shows a progressive decrease in the intensity of the left basal opacity and persistence of the previous cysts in the right and left lower lobes (arrows).

and left lower lobes (Figure 5C). An increase in serum level of E. granulosus $\operatorname{lgG} 6 \mathrm{U} / \mathrm{mL}(N<0.9 \mathrm{U} / \mathrm{mL})$ was found and $A$. fumigatus IgG was absent. A. niger was no longer isolated by sputum culture at that time.

After hospital discharge, the patient remained with no antibiotic, antifungal or antiparasitic medication till March 2019, when another exacerbation episode occurred. This time, the patient complained of severe cough and copious sputum production (Figure 6C), wheezing, fever and chest pain. On admission, chest radiography (Figure 6A and $B$ ) identified previous cavitary lesions increased in size and signs of ruptured cyst in the left upper lobe. Contrast-enhanced computed tomography (Figure 7) confirmed the intrabronchial rupture of left upper lobe cyst ('onion peel sign' or 'Cumbo' sign), and the increase in size of the left and right lower lobes cysts (suggestive for secondary infection). Since then, the patient has not experienced other exacerbations.

\section{Discussions}

Hydatid disease continues to be a challenging medical problem and it should be considered in the differential diagnosis of cystic pulmonary lesions (3). It commonly occurs in persons with a prolonged exposure to the intermediate hosts of Echinoccocus such as sheep or dogs. In most of the patients, pulmonary HCs remain asymptomatic and could be accidentally detected by chest radiography. Pulmonary HCs have a predilection for the right posterior lung segments, with $60 \%$ of cases manifesting in the lower lobes $(2,4)$. Pulmonary 


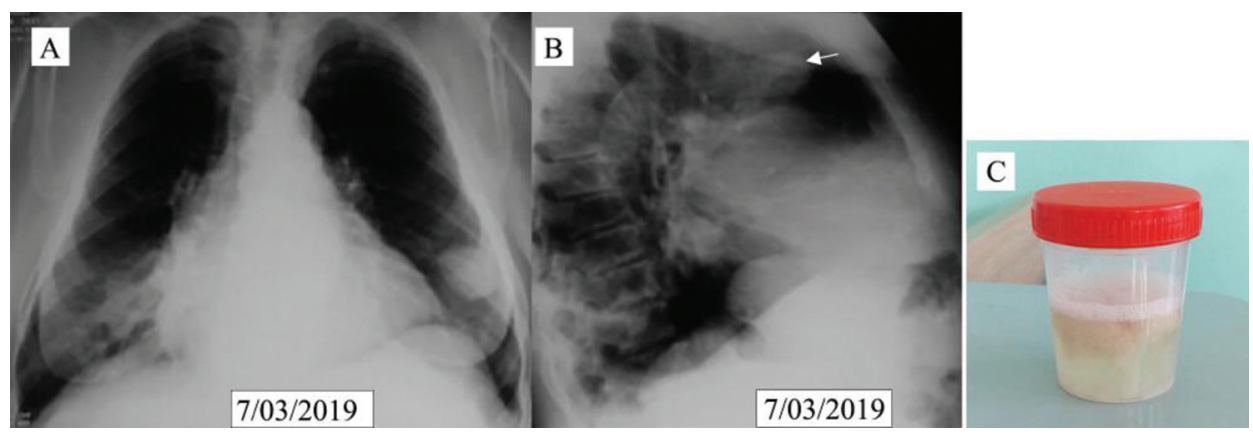

Figure 6. (A) Posteroanterior (PA) chest radiography shows increase in size and intensity of the left lower lobe mass, and change in shape and size of the right lower lobe mass surrounded by less intense opacity. (B) Lateral chest radiography identified the left upper lobe cyst (not visible on PA view) with small air foci suggestive for a ruptured cyst (arrow). (C) Three-layered sputum sample (a purulent sediment, clear middle liquid and a top foamy layer).

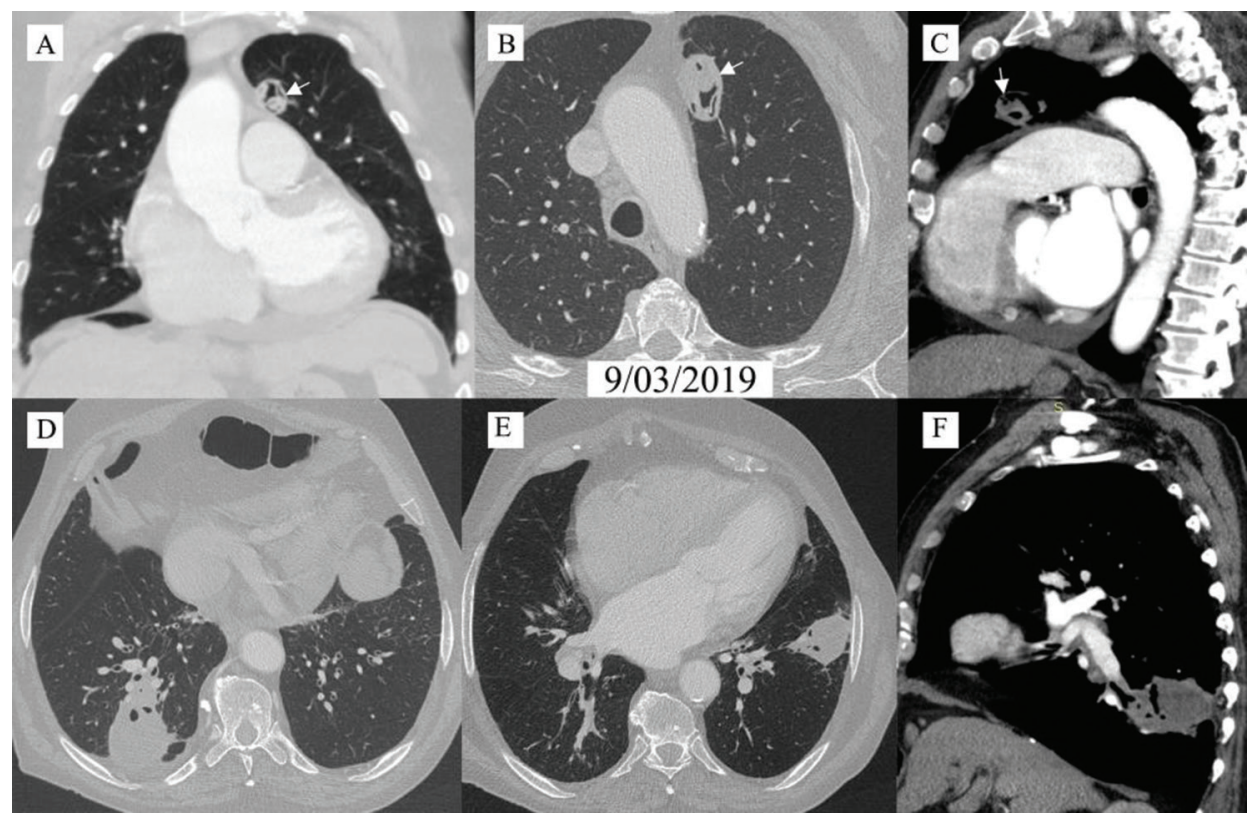

Figure 7. Contrast-enhanced computed tomography shows hydatid cyst in left upper lobe (A-C, arrows) completely ruptured ('onion peel' sign or 'Cumbo' sign - the gas lining between the endocyst and pericyst has the appearance of an onion peel). Note the increase in size of the left and right lower lobes cysts with 'air bubble' sign in both cysts suggestive for secondary infection.

echinococcosis becomes symptomatic when cysts grow to a certain size and produce a compression or when complications arise $(2,3,9)$. Common complications associated with HCs are rupture or infection $(6,10)$. Other rare complications such as pneumothorax, atelectasis, secondary echinococcosis of pleura or mediastinum or pulmonary embolism have also been reported (10). Both rupture and infection can be suspected on the basis of acute or subacute onset of clinical symptoms and suggestive imaging findings (6,9-11).

Symptoms associated with a complicated pulmonary hydatid disease include sudden onset of chest pain, cough, fever and haemoptysis. Perforation of the cysts into a bronchiole could result in hydatoptysis - expectoration of the germinative membrane or the hooklets of the parasite (4). Cough could be productive of purulent sputum in case of infection.

Pulmonary lesions have three components, and they are important for understanding the radiographic appearance of pulmonary HCs. The outermost part is called the pericyst and it consists of compressed lung tissue and fibrosis adjacent to the parasite. The parasite itself is composed of two layers, namely an outer layer or ectocyst and an inner layer or endocyst, from which daughter cysts bud. 
Radiological features of pulmonary hydatid disease vary from pure cystic lesions to a completely solid mass, which implies a large list of differential diagnosis that includes tuberculosis, primary and secondary tumours, lung abscess, bacterial bronchopulmonary infections, polyangiitis with granulomatosis, bronchiectasis, pneumothorax, pleurisy and empyema (10). Daughter cyst formation and calcification of the cyst walls are common in the liver but rare in the lung ( $1 \%$ of cases) $(4,10)$.

Although typical imaging findings have been well described in the literature, atypical imaging presentation can occur secondary to cyst rupture. Some authors suggested to differentiate the radiological features of ruptured $\mathrm{HCs}$ into contained cyst rupture signs (rupture of the pericyst which leads to dissection of air between the pericyst and ectocyst - 'air crescent' or 'meniscus' sign) and complete cyst rupture signs (rupture of the exocyst, with the expulsion of some fluid contents, allowing the endocyst to collapse - 'Cumbo', 'onion', 'whirl', 'water-lily', 'mass within a cavity', 'dry cyst' signs) $(11,12)$.

In case of infected HCs, radiography can show a thick-walled structure, similar to lung abscesses, with air-fluid level and a pneumonic consolidation area surrounding it. On $\mathrm{CT}$, an increase in density of cystic lesions ( $>20 \mathrm{HU})$ is suggestive for superimposed infection, making difficult the differentiation with abscess or tumour. 'Air bubble' sign could be helpful in this regard. The 'air bubble' sign is better seen in the mediastinal window and consists of single or multiple small rounded radiolucent areas with sharp margins within the periphery of a solid mass lesion $(4,13,14)$. It is caused by air entering into the cyst by erosion of the bronchiolar wall or gas production by secondary bacterial infection.

Routine haematological and biochemical tests show unspecific results in echinococcosis. Blood eosinophilia might occur in minority of patients when a leakage of antigen materials occurs $(3,15)$. In clinical practice, detection of specific serum IgG antibodies supports the diagnosis with a specificity ranging between $50 \%$ and $90 \%$. False-positive IgG results could be caused by other parasitic diseases. False-negative results are more common in pulmonary than in hepatic echinococcosis and they are associated with an intact, calcified or non-viable cyst (16). Complication with secondary infections requires specific additional laboratory workup.

Bacterial pneumonia is the most frequently reported secondary infection associated with pulmonary HCs. Commonly isolated bacterial germs belong to streptococci group $(5,6)$. In liver hydatids, infection with Escherichia coli, Enterococcus sp. and Staphylococcus aureus has also been reported (6). Fungal infection of the pulmonary HCs is very rare. Cases with Cryptococcus and Aspergillus association have been reported. Aspergillus coinfection is usually identified by imaging finding and supported by positive microbiological test (sputum culture or microscopy) and/or serological assay (antiAspergillus IgG) $(17,18)$.

Surgery, even in cases with bilateral involvement, is the treatment of choice in $\mathrm{HC}$ patients who can undergo intervention. Therapy with benzimidazoles (mebendazole or albendazole) is valuable in disseminated disease, high surgical risk patients and pre- and post-surgical prophylaxis. Evaluation of treatment success is difficult and it usually implies regular clinical and imaging follow-up. Assessment of serological titres could be helpful for therapy response monitoring (3).

Despite the apparently typical clinical presentation of lung echinococcosis, our case clearly illustrates the role of a detailed imaging assessment for a proper diagnosis and clinical decision-making. The variety of concomitant imaging appearances (intact cyst, 'air bubble', 'crescent', 'onion peel' signs) detected during the initial hospitalisation was crucial for further laboratory assessment and prompt diagnosis of a rare coexistence of echinococcosis and aspergillosis.

This case also illustrates clinical challenges in patients with $\mathrm{HC}$ who are not eligible for surgical treatment. One of the most significant points in this regard is the importance of regular imaging and microbiological follow-up, particularly important during exacerbation of each symptom. Thus, detailed follow-up imaging during exacerbation of symptoms in our patients was helpful for proving rupture of HCs and secondary bacterial coinfection. The evolution of radiological signs was useful for making decisions about the regression of fungal-bacterial coinfection on antibiotic treatment during the exacerbations.

In our patient, it was not possible to ensure a sustainable administration of antiparasitic and antimycotic medication due to side effects. However, antibiotic and antifungal medication for 1 month improved symptoms and diminished both lower lobe cysts size on follow-up CT 3 months later (Figure $4 \mathrm{C}-\mathrm{F}$ ). Currently, there is no generally accepted duration of antifungal treatment in cases of coexisting aspergilloma and pulmonary $\mathrm{HC}$ with no surgical treatment (19). This is partially due to the fact that majority of reported cases are diagnosed retrospectively after surgical removal of the cyst $(7,8,17,20)$. Further reporting of similar coinfected, surgically untreatable cases will contribute to a better management of these patients.

\section{Conclusion}

We have presented a case with multiple pulmonary echinococcal cysts, complicated by rupture and superimposed infections, which was treated medically. This is one of the few reports of a response to medical treatment alone in an adult patient with concurrent infections and multiple co-morbidities. 


\section{Patient's consent}

Patient's consent was obtained prior to publication of this article.

\section{Conflicts of interest}

No conflict of interest related to this article apply.

\section{References}

1. Agudelo Higuita NI, Brunetti E, McCloskey C. Cystic echinococcosis. Journal of Clinical Microbiology. 2016;54(3): 518-523.

2. Gottstein B, Reichen J. Hydatid lung disease (echinococcosis/ hydatidosis). Clinics in Chest Medicine. 2002;23(2): 397-408.

3. Morar R, Feldman C. Pulmonary echinococcosis. European Respiratory Journal. 2003;21(6): 1069-1077.

4. Sarkar M, Pathania R, Jhobta A, Thakur BR, Chopra R. Cystic pulmonary hydatidosis. Lung India. 2016;33(2): 179-191.

5. Trachsel D, Rutishauser M, Delfs-Jegge S, Hammer J. Pneumonia following rupture of echinococcal cyst: diagnosis with bronchoalveolar lavage. Pediatric Pulmonology. 1998;26(6): 434-437.

6. Garcia MB, Lledias JP, Perez IG, Tirado VV, Pardo LF, Bellvís LM, et al. Primary super-infection of hydatid cyst - clinical setting and microbiology in 37 cases. The American Journal of Tropical Medicine and Hygiene. 2010;82(3): 376-378.

7. Aala F, Badali H, Hashemi Fesharaki S, Boroumand M, Sotoudeh Anvari M, Davari H, et al. Coexistence of aspergilloma and pulmonary hydatid cyst in an immunocompetent individual. Journal de Mycologie Médicale. 2017;27(3): 396-399.

8. Mishra P, Malik A, Arora A, Dutta V. Aspergilloma in a pre-existing unoperated pulmonary echinococcosis. Medical Journal Armed Forces India. 2015;71(Suppl 1): S92-S94.

9. Sokouti M, Sokouti B, Sokouti M. The value of X-ray and CT scan in diagnosing pulmonary hydatid cyst. Clinical Imaging. 2013;37(5): 978.
10. Turgut AT, Altinok T, Topcu S, Koşar U. Local complications of hydatid disease involving thoracic cavity: imaging findings. European Journal of Radiology. 2009;70(1): 49-56.

11. Akgul Ozmen C, Onat S. Computed tomography (CT) findings of pulmonary hydatid cysts in children and the factors related to cyst rupture. Medical Science Monitor. 2017;23: 3679-3686.

12. Webb R, Higgins Ch. Thoracic Imaging. 2nd ed. Philadelphia: Wolters Kluwer/Lippincott Williams \& Wilkins Health; 2011: 914 p.

13. Das A, Das SK. "Air - bubble" sign - an uncommon presentation of a common disease. Journal of Global Infectious Diseases. 2011;3(3): 310-312.

14. Singh U, Kumar S, Gour H, Singh N, Ramaraj M, Mittal V, et al. Complicated hydatid cyst and "air bubble" sign: a stepping-stone to correct diagnosis. American Journal of Case Reports. 2015;16: 20-24.

15. Panaitescu D. Eosinophilia in hydatidosis. Archives roumaines de pathologie expérimentales et de microbiologie. 1970;29(3): 447-452.

16. Aydin Y, Altuntas B, Kaya A, Ulas AB, Uyanik MH, Eroglu A. The availability of echinococcus IgG ELISA for diagnosing pulmonary hydatid cysts. The Eurasian Journal of Medicine. 2018;50(3): 144-147.

17. Aliyali M, Badali H, Shokohi T, Moazeni M, Nosrati A, Godazandeh G, et al. Coinfection of pulmonary hydatid cyst and aspergilloma: case report and systematic review. Mycopathologia. 2016;181(3-4): 255-265.

18. Denning DW, Cadranel J, Beigelman-Aubry C, Ader F, Chakrabarti $\mathrm{A}$, Blot $\mathrm{S}$, et al. Chronic pulmonary aspergillosis: rationale and clinical guidelines for diagnosis and management. European Respiratory Journal. 2016;47(1): 45-68.

19. Alastruey-Izquierdo A, Cadranel J, Flick H, Godet $\mathrm{C}$, Hennequin $\mathrm{C}$, Hoenigl $\mathrm{M}$, et al. Treatment of chronic pulmonary aspergillosis: current standards and future perspectives. Respiration. 2018;96(2): 159-170.

20. Kocer NE, Kibar Y, Guldur ME, Deniz H, Bakir K. A retrospective study on the coexistence of hydatid cyst and aspergillosis. International Journal of Infectious Diseases. 2008;12(3): 248-251. 